\title{
SELF-ASSESSMENT THROUGH THE METACOGNITIVE AWARENESS PROCESS IN READING COMPREHENSION
}

\author{
Katerina Kasimatis ${ }^{1}$, \& Theodora Papageorgiou ${ }^{2}$ \\ ${ }^{I}$ School of Pedagogical and Technological Education, Department of Education, Associate Professor \\ (Greece) \\ ${ }^{2}$ School of Pedagogical and Technological Education, Department of Education, Tutor (Greece)
}

\begin{abstract}
In our study we investigate the relationship between adult self-assessment and the level of metacognitive awareness in reading comprehension. The sample of the research consisted of adults participating in a training program in order to obtain a certification of pedagogical competence, during the year 2017-2018. MARSI (Mokhtari \& Reichard, 2002) was used as a research tool and open - ended questions were distributed to the trainees. MARSI contains 30 questions and provides an overall indicator of the level of awareness of metacognitive reading strategies as well as individual indicators of metacognitive strategies in reading. In our study we focused on the overall index and the metacognitive development of the trainees. The questionnaire was completed in two phases during the year 2017-18. Both quantitative and qualitative analysis of the data was conducted. The statistical process of the data revealed the existing high level of awareness of metacognitive reading strategies (about $70 \%$ of students were identified at a high level, ie $\mathrm{M}>3.5$ ), which is also in accordance with the high quality educational level of the trainees (49.6\% had postgraduate / doctoral degrees) and their age $(\mathrm{M}=35)$. Concerning the effect of training on their metacognitive awareness, there has been a statistically significant increase in the overall average of MARSI, which indicates the positive impact of the training on a population of high educational level and of relatively older age than the normal trainee population. The qualitative analysis of the open questions revealed the enhancement of self-assessment among trainees as a dominant metacognitive skill, and significant conclusions were drawn regarding reading skills through the use of digital technologies, the way of study, the link between theory and practice, etc. It is of outmost importance the fact that the positive contribution of the training procedure to the metacognitive awareness of the participants appears to be focused only on those with pre-existing teaching experience in education structures who seem to have had been themselves more highly self-assessed. It is proposed to enrich such training actions with more self-assessment practices and techniques, when designing and implementing them in order to contribute to a further improvement of the metacognitive awareness of all the participants.
\end{abstract}

Keywords: Self-assessment, metacognitive awareness, metacognitive skills, reflection, reading skills.

\section{Introduction}

Metacognition was firstly introduced by Cognitive Psychologists in the 1960s and then transferred into Evolutionary Psychology represented by Flavell in 1976. Flavell defined it as "meta-memory", after studying children's and adolescents' knowledge regarding the processes of memory. Thenceforth, many definitions have been raised for metacognition which reveal the deeper meaning of the word and correlate memory, learning and understanding. It is defined as "the knowledge and understanding that one has on the level and the possibilities of his thought, his personal information processing system and the construction of knowledge" (Koutselini - Ioannidou, 1995:48) or as "the people's knowledge about what they know, remember and think" (Metcalfe\&Shimamura, 1994: xi). Furthermore, according to Kassotakis and Flouris (2006) metacognition is the awareness of knowledge conquered, the ways by which they acquired them and their results. In other words, it is one's ability to develop strategies to be aware of the steps of "cognition", to monitor and control these steps, and regulate them so as to effectively solve the specific problems that arise and assess results and the course of his thought. Meichenbaum, Burland, Gruson\& Cameron (1985), still consider that metacognition is "the awareness we have of our cognitive mechanisms and how they work". 
According to Flavell (1979) "Meta-cognition is defined as the cognition of cognition" but there are many other approaches, such as "thinking about thinking", "knowledge about knowledge" or "people's knowledge about what they know, remember and think" (Metcalfe\&Shimamura, 1994). The prefix "meta" of the word, characterizes the process of knowledge in a second level. This way, the cognitive and metacognitive skills get desegregated. Cognitive skills are perception, memory, performance, cognition, language, critical acumen, problem solving, decision making and critical thinking. The metacognitive skills on the other hand, "assist the understanding and awareness of the learning process and regulate the performance in terms of processing and assimilating new knowledge". These are two interrelated processes that cannot be considered as separated parts.

In addition, according to Paris\&Winograd (1990) "Metacognition introduces two key features: Self-assessment and self-management of mind. Self-assessment refers to the theoretical aspect of metacognition, and in particular to the personal reflections that people make about their mental states, motives and traits as traumatized. Such reflections refer to "what do I know?" Questions, like "how do I think?" And "when and how can I apply specific learning strategies?" (Paris\&Winograd 1990, p. 17)

On the other hand, self-management refers to the practical form of metacognition, namely the mobilization of the mental processes responsible for the orchestration of various aspects of problem solving process, the alternative designs that the laymen organize before dealing with a work, the adaptations they make while working on the revisions they make after completing their work (as above p. 18).

Baker \& Brown recognized (1984) the important role of metacognition in understanding the content of a text by storing information in memory. Cross \& Paris (1988), have highlighted the important role of metacognitive monitoring and control in achieving reading comprehension. Finally, Kolic-Vehovec, (2010) has shown that metacognitive awareness and the skills of reading strategies, when developed parallel to reading ability, can enhance reading comprehension, and it could be considered that metacognition can predict levels of reading comprehension.

\section{Method}

Both quantitative and qualitative analysis of the data was conducted. For the quantitative analysis of the data, the variable scales are described using the mean value, while the ordinates are referenced by the MARSI total index. Parameter testing of t-test dependent samples (regularity analysis confirms the use of parametric methods). The qualitative study was considered appropriate because the researchers were keen on investigating trainees' skills. The study maintained a particular interest for the metacognitive skills developed through the trainee participation in the Program. All recorded data was analyzed by thematic analysis (Creswell, 2000). This approach supplies a frame work for the thematic analysis of qualitative data and provides one way of thinking about how to manage themes and data; this process is likely to reflect the analyst's awareness of recurring ideas and topics in the data (Bryman, p.587).

\subsection{Participants}

The sample of the research consisted of 245 adults participating in a training program in order to obtain a certification of pedagogical competence, during the year 2017-2018. The trainees were of different specialty, such as Nurses, Civil Engineers, Doctors, Teachers, Lawyers, Economists, Accountants, etc.

\subsection{Instrument}

MARSI (Mokhtari \& Reichard, 2002) was used as a research tool and open -ended questions were distributed to the trainees. MARSI contains 30 questions and provides an overall indicator of the level of awareness of metacognitive reading strategies as well as individual indicators of metacognitive strategies in reading. A Metacognitive Awareness of Reading Strategies Inventory (MARSI) was translated and validated to greek student population (Koulianou, Roussos, Samartzi, In Press). In our study we focused on the overall index and the metacognitive development of the trainees. It refers to a selection from a scale in statements related to the relative reading strategy, which took place during the reading process and consists of 30 questions. The self-report tool consists of three types of strategies: (a), problem-solving strategies (b) global and (c) support. Each of the strategies is associated with one of the three subcategories. Problem Solving Strategies (8 questions), Global Reading Strategies (13 questions), Support Reading Strategies (9 questions).

The questionnaire was completed in two phases during the year 2017-18, in the beginning and at the end of the training program. Of these 240 were complete, while in five of them qualitative questions were missing. 


\subsection{Objectives and Research questions}

In our study we investigate the relationship between adult self-assessment and the level of metacognitive awareness in reading comprehension.

- What is the level of metacognitive awareness in reading comprehension of the trainees and how this evolves during their participation in the training program?

- How does the existing teaching experience of students affect the development of metacognitive awareness in reading comprehension?

- What is the relationship between development of the metacognitive awareness of reading strategies and self-assessment?

\section{Results}

As far as the level of metacognitive awareness in reading comprehension of the trainees and how this evolves during their participation in the training program is concerned, the statistical analysis of the data revealed the existing high level of awareness of metacognitive reading strategies (about $70 \%$ of students were indicated at a high level, ie M> 3,5), which is consistent with the high educational level the trainees $(49,6 \%$ holders of postgraduate / doctoral degrees), as well with the age of the trainees $(\mathrm{M}=35, \mathrm{SD}=7)$.

The specialty of the trainees is related to the negative attitude towards reflection, something that is mentioned particularly in the department of Nurses (a very high percentage didn't answer at all and a very high percentage had a negative attitude towards the influence of the Questionnaire and the program. So, we have to further investigate the representations of the different specialties regarding reading and metacognitive skills and their contribution to the educational process.

Regarding the impact of the teaching experience on the metacognitive experiences of students participating in the program, statistic analysis did not reveal significant statistical differentiation in relation to the studies of the trainees. Of particular interest is the fact that positive differentiation is associated only with those trainees who have teaching experience in educational institutions or in non-formal education.

Figure 1. Evolution of MARSI.

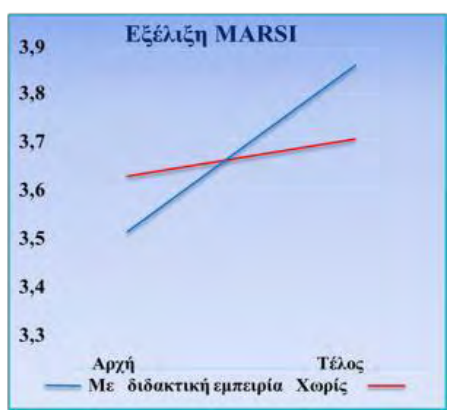

As far as the impact of the training program on the metacognitive awareness of trainees is concerned, there has been a statistically significant increase in the overall average of MARSI, which indicates the positive impact of the training on a population of high educational level and of relatively older age than the normal trainee population. More specifically, although the level did not statistically significantly change $[$ Mdnpre $=3.0$, Mdnpost $=3.0($ where ' 3 ' $=$ high), $\mathrm{z}=-0.536, \mathrm{P}=0.607$ ) there was a statistically significant increase in the total mean MARSI [Mpre $=3.62$, Mpost $=3.75$ (in the range 1 to 5), $\mathrm{t}(243)=-2.507, \mathrm{P}=0.013$ ]

The qualitative analysis of the open - ended questions revealed the enhancement of self-assessment among trainees as a dominant metacognitive skill, and significant conclusions were drawn regarding reading skills through the use of digital technologies, the way of study, the link between theory and practice, etc. It is of outmost importance the fact that the positive contribution of the training process to the metacognitive awareness of the participants appears to be focused only on those with pre-existing teaching experience in educational structures who seem to have been more highly self-assessed.

Regarding the correlation of the improvement of reading skills with the use of digital technologies there is a positive correlation between the reading skills in comprehension during the implementation of the program and digital technologies. There was a variety in the terms they used to describe digital technologies such as: technologies, internet, computer, website, Wikipedia. Negative 
correlation between specialty and digital technologies is noted only in departments of Nurses and Electrical Engineers, where there wasn't any mention of digital technologies at all.

Regarding the way of studying, we are led to the conclusion that the development of the metacognitive awareness changed their way of studying: "Certainly it helped me understand some actions that I do unintentionally" "I will try to abolish the bad habit I have when I don't understand the meaning of a text, abandoning any effort. Now, I will insist on trying to understand the meaning."

The trainees, also, learned to link theory with practice: "I was more focused on how the theory is related to the practice and I gained a more critical judgment on the content of all the modules I have been taught." "I believe that things I made unintentionally, now I am able to put them in order and I will use some helpful ways of studying more consciously"

The answers of the participants revealed the fact that although they used to use self - reflective processes in reading they didn't know the terminology of them. "I didn't change my way of studying because I think it is effective. They only new thing I acquired from the program is the fact that I learned the terminology."

The answers of participants, also, revealed the important role of metacognitive awareness in the real life and in professional development. "I manage my time better, I do not postpone things for later. I will try to be more organizational and not postpone things in the future". "I stated to read having a specific goal in my mind and identifying the elements that were important for me as a student as well as a professional"

As far as the importance of metacognition is concerned, the trainee leads to an epistemological and ontological assumption of great importance for education that "everything around us is Knowledge". "I learned to read using keywords. In the second semester I was helped to understand that everything around me is knowledge".

The trainee acquires a metacognitive awareness of the importance of associations, understanding the way we establish new knowledge in the long-term memory, a basic pedagogical and theoretical assumption of the processes that we use in order to learn. "I have been collaborating to remember what I am reading and to understand in depth the meaning of the text".

\section{Discussion}

The qualitative analysis of trainees' response data revealed that the trainees developed metacognitive skills in reading comprehension. More specifically, the trainees learned to monitor and control the Knowledge, something which is in accordance with Cross \& Paris (1988), who have highlighted the important role of metacognitive monitoring and control in achieving reading comprehension.

The trainees in most of their responses stressed the importance of metacognition awareness for their life and their professional development. They developed metacognitive skills, as reflected in their responses to the transfer of knowledge to their future lives and similar situations. Furthermore, they developed the ability to dedicate their time to learning, autonomy, discipline, perseverance, and information management in the learning process, which are basic skills in the Deustro (2008) model, as well as in the (Binkley et.al., 2012) model.

According to the theory of Rosenblatt (1938/1970: viii-i) which refers to literary experience, reading experience is described as a kind of intense personal activity, a means of personal exploration, of nature, of mental and emotional abilities, of the outside world, as well as alternative ways of life.

Regarding the correlation of the reading skills with the use of digital technologies the findings revealed the improvement of reading skills during the implementation of the program with the use of the digital technologies. More specifically, in terms of computer use, they developed skills related to the use of text as well as other more specialized software and they realized the correlation between reading skills in comprehension and digital technologies, which are basic in the Deustro model (2008).

In Greece the MARSI has been used in teenagers with or without learning difficulties, with satisfactory validity and reliability (Koulianou, Roussos \& Samartzis, in issue). In our study, the innovation lies in the fact that the MARSI was used in a population of adults with particular characteristics. Finally, they approached a higher level of reading comprehension during the implementation of the program and they developed critical thinking, as their answers revealed. 


\section{Conclusions}

In general, the qualitative analysis of open - ended self-assessment questions revealed the enhancement of self-assessment as the most important metacognitive skill. It is of outmost importance the fact that the positive contribution of the training program to the metacognitive awareness of the participants appears to be focused only on those with pre-existing teaching experience in education structures who seem to have had themselves more highly self-assessed. So, it is proposed to enrich such training actions with more self-assessment practices and techniques, when designing and implementing them in order to contribute to a further improvement of the metacognitive awareness of all the participants. It is, also, suggested an analysis of the level of each different cognitive specialty. Finally, it is pointed out the need to further explore the representations of the different specialties for reading and metacognitive skills and their contribution to the educational process.

The author Katerina Kasimatis acknowledge financial support for the dissemination of this work from the Special Account for Research of ASPETE through the funding program "Strengthening ASPETE's research".

\section{References}

Ana Garcva Olalla, Gonzalo Malla Mora, Josı Antonio MarvnParedes,Josı Moya Otero, M. Isabel Mupoz San Ildefonso, Manuel Poblete Ruiz, Josu Solabarrieta Eizaguirre Aurelio Villa Sanchez (2008), Competence-based learning. A proposal for the assessment of generic competences, Spain: University of Deusto

Baker, L., \& Brown, A. L. (1984). Metacognitive skills and reading. $\Sigma \tau$ o P. D. Pearson, R. Barr, M. L. Kamil, \& P. Mosenthal, Handbook of reading research (pp. 353 - 394). New York, NJ: Longman.

Binkley, M., Erstad, O., Herman, J., Raizen, S., Ripley, M., Miller-Ricci, M., Rumble, M., (2012). Defining Twenty-First Century Skills. In B. McGaw \& E. Care (Eds), Assessment and Teaching of 21st Century Skills (pp 17-.66). New York, NY: Springer

Bryman, A. (2016). Social Research Methods, Oxford: Online Research Centre

Creswell, J. W. (2000). Research design. Sage, 1-246. https://doi.org/10.1016/j.math.2010.09.003

Cross, D. R., \& Paris, S. G. (1988). Developmental an instructional analysis of children's metacognition and reading comprehension. Journal of Educational Psychology, 80, 131-142. doi:10.1037/0022-0663.80.2.131

Flavell, J. H. (1979). Metacognition and Cognitive Monitoring: A new area of Psychological Inquiry. American Psychologist, 34, 906-911.

Koutselini - Ioannidou, M. (1995). Metacognition: Concept and teaching. New Education, 74, p. 48 - 56.

Kassotakis, M. \&Flouris, G. (2006). Learning and Teaching. Athens: Private Edition.

Kolic-Vehovec, S., (2010). Self-monitoring and attribution training with poor readers. Studia psychologica 44 (1), 57-68, 2002.

Koulianou, Roussos, Samartzi, (In Press). Metacognitive Reading Strategies: Greek adaptation of the MARSI and a comparative study of adolescent students with and without special learning difficulties. Psychology.

Meichenbaum, D. Burland, S. Gruson, L., \& Cameron, R. (1985). Metacognitive Assessment. In: Youssen S (Ed.), The Growth of Reflection in Children. Orlando, Fl.: Academic Press, p. 5.

Metcalfe, J., \&Shimamura, A. P. (1994). Metacognition: knowing about knowing. Cambridge, MA: MIT Press.

Mokhtari, K., \& Reichard, C. (2002). Assessing students,, metacognitive awareness of reading strategies. Journal of Educational Psychology, 94(2), 249-259.

Paris, S. G., \& Winograd, P. (1990). How metacognition can promote academic learning and instruction. In B. F. Jones \& L. Idol (Eds.), Dimensions of thinking and cognitive instruction (pp. 15-51). Hillsdale, NJ, US: Lawrence Erlbaum Associates, Inc. 